\title{
Co-Incubation of Human Spermatozoa with Anti-VDAC Antibody Reduced Sperm Motility
}

\author{
Bianjiang Liu Min Tang Zhijian Han Jie Li Jiexiu Zhang Pei Lu Ninghong Song \\ Zengjun Wang Changjun Yin Wei Zhang
}

State Key Laboratory of Reproductive Medicine and Department of Urology, The First Affiliated Hospital of Nanjing Medical University, Nanjing, China

\section{Key Words}

VDAC $\cdot$ Human $\cdot$ Sperm motility $\cdot$ Calcium $\bullet \mathrm{pH} \cdot$ ATP

\begin{abstract}
Background: Voltage-dependent anion channel (VDAC), a channel protein, exists in the outer mitochondrial membrane of somatic cells and is involved in multiple physiological and pathophysiological processes. Up until now, little has been known about VDAC in male germ cells. In the present study, the relationship between VDAC and human sperm motility was explored. Methods: Highly motile human spermatozoa were incubated in vitro with antiVDAC antibody. Total sperm motility, straight line velocity (VSL), curvilinear velocity (VCL), and average path velocity (VAP) were recorded. Intracellular free calcium concentration $\left(\left[\mathrm{Ca}^{2+}\right]_{\mathrm{i}}\right)$, $\mathrm{pH}$ value $(\mathrm{pHi})$, and ATP content were determined. Results: Co-incubation with anti-VDAC antibody reduced VSL, VCL, and VAP of spermatozoa. Co-incubation further reduced $\left[\mathrm{Ca}^{2+}\right]_{i}$. Anti-VDAC antibody did not significantly alter total sperm motility, pHi and intracellular ATP content. Conclusion: The data suggest that co-incubation with anti-VDAC antibody reduces sperm motility through inhibition of $\mathrm{Ca}^{2+}$ transmembrane flow. In this way, VDAC participates in the modulation of human sperm motility through mediating $\mathrm{Ca}^{2+}$ transmembrane transport and exchange.
\end{abstract}


Liu et al.: VDAC and Human Sperm Motility

\section{Introduction}

The voltage-dependent anion channel (VDAC), a channel protein, exists extensively in the mitochondrial outer membranes of different species [1]. VDAC is involved in multiple physiological and pathophysiological processes, including energy metabolism and cell apoptosis [2,3]. VDAC performs biological functions by regulating the permeability of mitochondrial membrane to ions and small molecules, such as $\mathrm{Na}^{+}, \mathrm{K}^{+}, \mathrm{Ca}^{2+}, \mathrm{Cl}^{-}, \mathrm{ATP}$, glutamate, succinate, and malate $[2,4,5]$. In addition, VDAC is also reported to exist in cellular plasma membrane besides the mitochondria, which implies that VDAC has other unexpected functions [6-8]. Although VDAC has been studied extensively in somatic cells, little is known about VDAC in male germ cells. Few recent studies have shown that VDAC exists in mammalian spermatozoa and participates in spermatogenesis, maturation, and fertilization [9-14]. However, the exact distribution and function of VDAC in mammalian spermatozoa, especially in human spermatozoa, remain unclear.

Normal sperm motility is the key premise of successful fertilization process. During sperm capacitation and sperm-egg binding in the female reproductive tract, spermatozoa are hyperactivated. This is also known as the activation of sperm motility. This hyperactivation is characterized by high-amplitude asymmetrical beating of the flagella, which helps the sperm penetrate the cervical mucus and the extracellular membrane of the oocyte and to complete sperm-egg binding. Computer-assisted semen analysis (CASA) has been used to assess sperm motility. The motility, straight line velocity (VSL), curvilinear velocity (VCL), and average path velocity (VAP) are some of the most important parameters of sperm motility used in CASA. The latter three indexes are also the hyperactivation parameters. Sperm motility can be triggered by environmental cues, including ions and micromolecules $\left(\mathrm{pH}, \mathrm{Ca}^{2+}, \mathrm{Na}^{+}, \mathrm{K}^{+}\right.$, cyclic nucleotides) [15]. Different transmembrane ion channels in the plasma membrane have been shown to participate in the regulation of sperm motility by changing the distribution of these cues, the difference in membrane potential, and the osmolarity inside and outside of the cell [15]. The concentration of intracellular free calcium ([Ca $\left.{ }^{2+}\right]$ i) and $\mathrm{pH}(\mathrm{pHi})$ are essential to maintaining normal sperm motility $[16,17]$. ATP provides the energy for sperm movement. Sperm motility has a positive correlation with intracellular ATP content [18]. Appropriate $\left[\mathrm{Ca}^{2+}\right]_{\mathrm{i}^{\prime}} \mathrm{pHi}$, and intracellular ATP content depend on normal transmembrane transport and exchange of $\mathrm{Ca}^{2+}, \mathrm{H}^{+} / \mathrm{HCO}_{3}{ }^{-}$, and ATP mediated by relative transmembrane ion channels.

Mammalian spermatozoa are highly compartmentalized. The proteins for acrosome reaction are usually present in the head or acrosomal region of the sperm. The proteins for sperm-egg fusion generally exist in the equatorial region. The proteins for sperm motility are located specifically in the sperm flagellum. Several studies have reported that VDAC exists in the tails of mice sperm and is related to sperm motility $[14,19]$. Mice lacking VDAC3 are infertile with markedly reduced sperm motility and altered structure within sperm axoneme [19]. VDAC is a typical transmembrane ion channel. VDAC in somatic cells participates in transmembrane transport of $\mathrm{Ca}^{2+}$ and ATP [2, 20-22]. Co-incubation of bull spermatozoa with anti-VDAC antibody impairs normal cell morphology and function when the concentration of intracellular ions changes [11]. A previous series of studies performed by the present team focused on the existence and function of VDAC in human spermatozoa. VDAC was shown to exist in the tails of human sperm and to be involved with the sperm acrosome reaction through mediation of $\mathrm{Ca}^{2+}$ transmembrane transport $[23,24]$. These data suggest that VDAC regulates sperm motility through mediation of transmembrane transport and exchange of relative ions and molecules. The aim of present study is to explore the relationship between VDAC and human sperm motility.

\section{Materials and Methods}

Approval for this study was granted by the ethics committee of Nanjing Medical University (China) prior to sample collection. Informed written consent was received from all participants of this study. All of 
Liu et al.: VDAC and Human Sperm Motility

the chemicals and reagents used in this study were of molecular biology grade and purchased from SigmaAldrich (St. Louis, MO, U.S.) except where otherwise stated.

\section{Spermatozoa preparation}

Freshly ejaculated human semen samples were obtained from fertile donors by masturbation after 5-7 days of sexual abstinence. All samples showed normal semen parameters according to 2010 World Health Organization guidelines [25]. Liquefied ejaculate was purified on a two-layer ( $90 \%$ and $45 \%$ ) discontinuous Percoll gradient (GE Healthcare, Piscataway, NJ, U.S.). After centrifugation at $300 \mathrm{~g}$ for $20 \mathrm{~min}$, the cell pellet from the 90\% layer was washed twice in Biggers-Whitten-Whittingham medium (BWW; $95 \mathrm{mM} \mathrm{NaCl} / 44 \mu \mathrm{M}$ sodium lactate/25 mM NaHCO 3 /20 mM Hepes/5.6 mM D-glucose/4.6 mM KCl/1.7 mM CaCl$/ 2 / .2 \mathrm{mM}$ $\mathrm{KH}_{2} \mathrm{PO} 4 / 1.2 \mathrm{mM} \mathrm{MgSO}{ }_{4} / 0.27 \mathrm{mM}$ sodium pyruvate $/ 0.3 \% \mathrm{wt} / \mathrm{vol} \mathrm{BSA}, 5$ units per ml penicillin $/ 5 \mu \mathrm{g} / \mathrm{ml}$ streptomycin, $\mathrm{pH}$ 7.4). The sperm pellet was then resuspended in BWW medium and adjusted to different concentrations.

\section{Immunofluorescence}

Sperm suspensions from 5 donors were prepared as above, air-dried onto poly-lysine-coated slides, and fixed with $4 \%$ paraformaldehyde in phosphate-buffered saline (PBS) for $1 \mathrm{~h} \mathrm{at} 4^{\circ} \mathrm{C}$. After washing with PBS, slides were blocked in goat serum (Zhongshan Goldenbridge Biotechnology, Beijing, China) for $2 \mathrm{~h}$ and incubated with rabbit anti-human VDAC antibody or normal rabbit IgG as the control (1:50; Santa Cruz Biotechnology, Santa Cruz, CA, U.S.) overnight at $4^{\circ} \mathrm{C}$. After incubated with goat anti-rabbit IgG conjugated to FITC (1:200; Santa Cruz Biotechnology, Santa Cruz, CA, U.S.) in dark room for $1 \mathrm{~h}$ at room temperature, slides were washed, coverslipped, and viewed with an Axioskop 2 plus fluorescent microscope (Carl Zeiss, Thornwood, NY, U.S.).

\section{Evaluation of sperm motility}

The effect of anti-VDAC antibody on sperm motility was monitored using a computer-assisted semen analyzer (IVOS; Hamilton-Thorne, Beverly, MA, U.S.). Sperm suspensions $\left(20 \times 10^{6}\right.$ cells $/ \mathrm{ml}$ ) from 5 donors were loaded with rabbit anti-human VDAC antibody or normal rabbit IgG antibody as the control at the final concentrations equivalent to 1,5 , and $20 \mu \mathrm{g} / \mathrm{ml}$. After 1,2 , and $3 \mathrm{~h}$ incubation in a $5 \% \mathrm{CO}_{2}$ incubator at $37^{\circ} \mathrm{C}$, aliquots of $10 \mu \mathrm{l}$ sperm suspensions from two groups were loaded on a 10- $\mu \mathrm{m}$-deep MicroCell counting chamber (Conception Technologies, San Diego, CA, U.S.) and analyzed in replicates at $37^{\circ} \mathrm{C}$. Four parameters (total sperm motility, VSL, VCL, and VAP) were recorded. A minimum of 200 spermatozoa were counted for each assay.

\section{Measurement of $\left[\mathrm{Ca}^{2+}\right]_{i}$}

$\left[\mathrm{Ca}^{2+}\right]$ i in spermatozoa was detected using fluo-3 AM and a FACSCalibur ${ }^{\mathrm{TM}}$ flow cytometer (BD Biosciences, San Jose, CA, U.S.). After $3 \mathrm{~h}$ of incubation with $20 \mu \mathrm{g} / \mathrm{ml}$ normal IgG or anti-VDAC antibody, as described above, sperm suspensions from 8 donors were loaded with fluo-3 AM ( $5 \mu \mathrm{M}$ final concentration; Invitrogen, Carlsbad, CA, U.S.) at $37^{\circ} \mathrm{C}$ for $30 \mathrm{~min}$ and washed twice with $\mathrm{BWW}$ at $500 \mathrm{~g}$ for $5 \mathrm{~min}$ to remove free fluo-3 AM. The fluorescence of Fluo-3 was excited at $488 \mathrm{~nm}$ and measured using a $530 \mathrm{~nm}$ filter. Photomultiplier tube voltages and gains were set to optimize the dynamic range of the signal. The fluorescence intensity was quantified for 10,000 individual spermatozoa.

\section{Measurement of $\mathrm{pHi}$}

After incubation for $3 \mathrm{~h}$ with $20 \mu \mathrm{g} / \mathrm{ml}$ normal IgG or anti-VDAC antibody in BWW medium with or without $\mathrm{HCO}_{3}^{-}, 2^{\prime}, 7^{\prime}$-bis-2(2-carbosyethyl)-5-(and-6)-carboxyfluorescein, acetoxymethyl ester (BCECF AM, $10 \mu \mathrm{M}$ final concentration; Invitrogen, Carlsbad, CA, U.S.) was added to sperm suspensions from 8 donors and incubation continued for $30 \mathrm{~min}$. Then the cells were washed twice to remove free dye. The fluorescence signal was recorded using an Infinite M200 Microplate Reader (Tecan Group, Männedorf, Switzerland). The pHi was obtained by ratiometric analysis of fluorescence data using a dual excitation wavelength of $490 / 440 \mathrm{~nm}$ and an emission wavelength of $535 \mathrm{~nm}$ ( $5 \mathrm{~nm}$ excitation/emission bandpass). Calibration was performed as previously described [26]. 
Fig. 1. Binding of anti-VDAC antibody to human spermatozoa shown by immunofluorescence. A-B: Spermatozoa were incubated with anti-VDAC antibody and second antibody conjugated to FITC. Intense staining was observed on the midpiece surface of sperm flagellum. C-D: Spermatozoa were incubated with normal IgG and second antibody conjugated to FITC. No obvious staining was observed in spermatozoa. A and C: Phase-contrast images. B and D: Immunofluorescent photomicrographs. Magnification is $\times 1000$. A representative experiment is shown. $\mathrm{n}=5$.

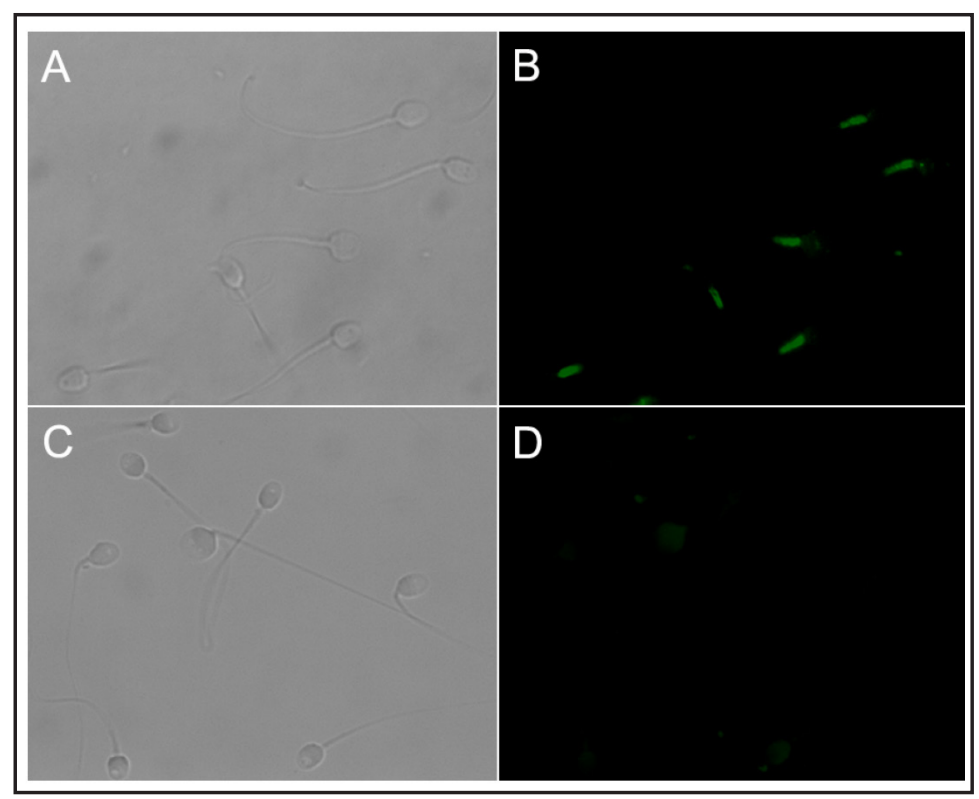

Measurement of intracellular ATP content

Intracellular ATP content was detected using an ATP Assay Kit (Beyotime Institute of Biotechnology, Shanghai, China). Spermatozoa from 8 donors were incubated for $3 \mathrm{~h}$ with $20 \mu \mathrm{g} / \mathrm{ml}$ normal IgG or antiVDAC antibody and lysed according to the manufacturer's instructions. After centrifugation at $12,000 \mathrm{~g}$ for $10 \mathrm{~min}$ at $4^{\circ} \mathrm{C}$, the supernatant was removed and mixed with dilution buffer containing luciferase. The relative light unit was measured by an Orion Microplate Luminometer (Berthold Technologies, Bad Wildbad, Germany) according to the manufacturer's instructions. A fresh standard curve was prepared each time and ATP content was estimated using the curve.

\section{Statistical analysis}

Data are expressed as mean \pm SEM. Differences between groups were assessed by a paired $t$ test. Statistically significant difference was determined at $P<0.05$.

\section{Results}

Immunofluorescence was initially performed to assess the affinity and binding site of anti-VDAC antibody to human spermatozoa. As shown in Fig. 1B, intense staining existed on the midpiece surface of sperm flagellum. No obvious staining was observed in control spermatozoa (Fig. 1D).

The effect of anti-VDAC antibody to sperm motility was recorded in Fig. 2. Three movement parameters (VSL, VCL, and VAP) showed no difference between spermatozoa incubated with $20 \mu \mathrm{g} / \mathrm{ml}$ anti-VDAC antibody and spermatozoa treated with $20 \mu \mathrm{g} / \mathrm{ml}$ normal rabbit IgG after $1 \mathrm{~h}$ incubation. Although the VSL of spermatozoa incubated with anti-VDAC antibody decreased significantly after $2 \mathrm{~h}$ of incubation, there was no obvious difference in VCL or VAP. After $3 \mathrm{~h}$ of incubation, VSL, VCL, and VAP of spermatozoa incubated with antiVDAC antibody were significantly lower than those treated with normal rabbit IgG. However, no obvious change in total sperm motility was detected (Table 1). No significant differences in VSL, VCL, VAP, or total sperm motility were observed when samples were incubated with 1 or $5 \mu \mathrm{g} / \mathrm{ml}$ antibody (data not shown).

To further evaluate the mechanism of antibody-impaired sperm motility, $\left[\mathrm{Ca}^{2+}\right]_{\mathrm{i}}, \mathrm{pHi}$, and intracellular ATP content were measured on spermatozoa incubated with $20 \mu \mathrm{g} / \mathrm{ml}$ anti- 


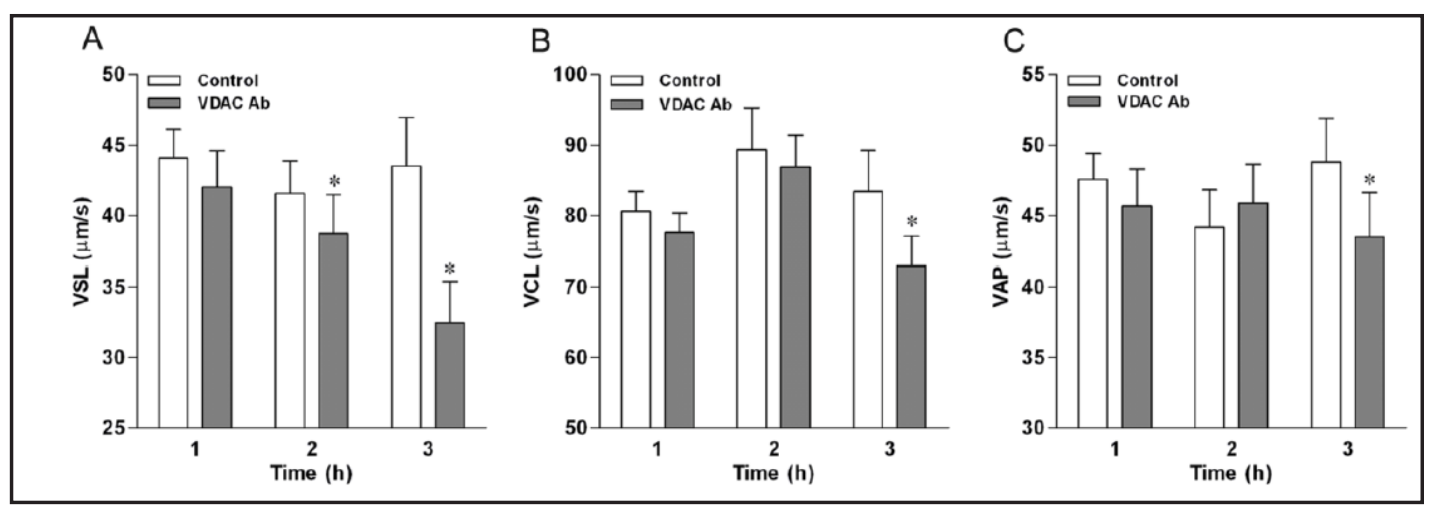

Fig. 2. VSL, VCL, and VAP of human spermatozoa incubated with $20 \mu \mathrm{g} / \mathrm{ml}$ normal IgG or $20 \mu \mathrm{g} / \mathrm{ml}$ antiVDAC antibody for $3 \mathrm{~h}$. Spermatozoa were analyzed using CASA. Data were shown as mean \pm SEM. $\mathrm{n}=5$; $*, P<0.05$.

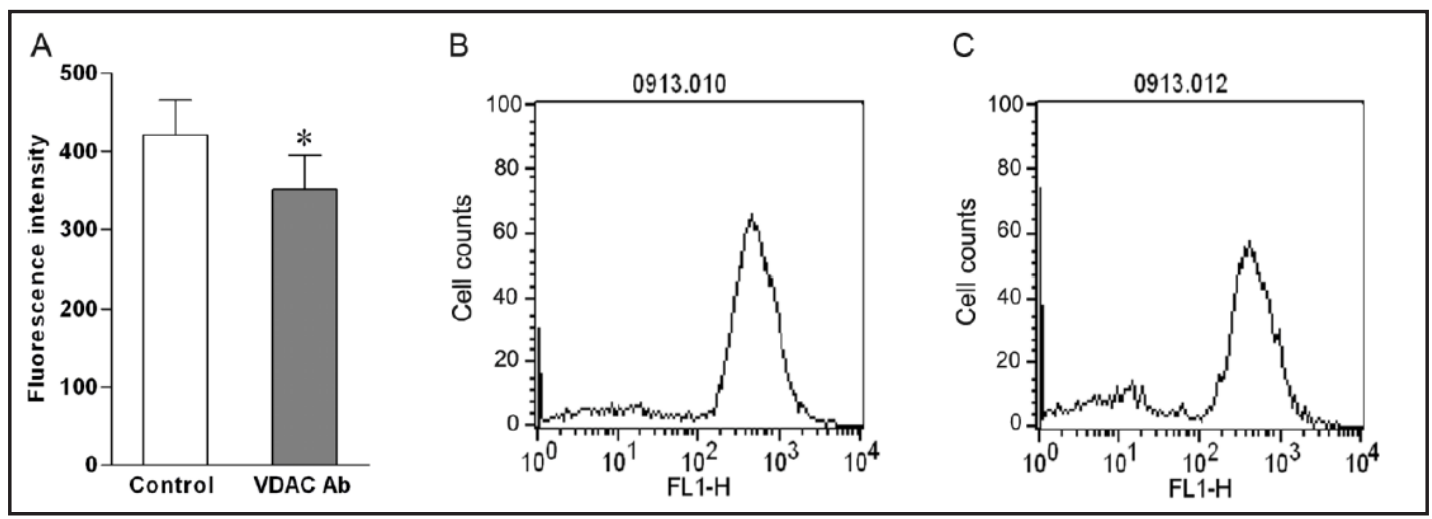

Fig. 3. A: $\left[\mathrm{Ca}^{2+}\right]_{\mathrm{i}}$ fluorescence intensities of human spermatozoa incubated with $20 \mu \mathrm{g} / \mathrm{ml}$ normal IgG and $20 \mu \mathrm{g} / \mathrm{ml}$ anti-VDAC antibody for $3 \mathrm{~h}$. B and C: Representative fluorescence intensity patterns of fluo-3 AM loaded spermatozoa incubated with (B) normal IgG and (C) anti-VDAC antibody. Spermatozoa were measured using a flow cytometer. Data are shown as mean \pm SEM. $\mathrm{n}=8 ; *, P<0.05$.

Table 1. Total sperm motility incubated with $20 \mu \mathrm{g} / \mathrm{ml}$ normal IgG or $20 \mu \mathrm{g} / \mathrm{ml}$ anti-VDAC antibody for $3 \mathrm{~h}$. Data are shown as mean \pm SEM; $\mathrm{n}=5$

\begin{tabular}{ccc}
\hline Incubation time & Control & Antibody incubation \\
\hline $1 \mathrm{~h}$ & $86.45 \pm 4.01$ & $88.21 \pm 1.93$ \\
$2 \mathrm{~h}$ & $91.38 \pm 3.47$ & $89.20 \pm 2.56$ \\
$3 \mathrm{~h}$ & $90.23 \pm 1.64$ & $88.20 \pm 1.48$ \\
\hline
\end{tabular}

VDAC antibody or normal rabbit IgG for $3 \mathrm{~h}$. As shown in Fig. 3, the $\left[\mathrm{Ca}^{2+}\right]_{\mathrm{i}}$ of spermatozoa incubated with anti-VDAC antibody was significantly lower than that of spermatozoa treated with normal rabbit IgG. There was no statistical difference in pHi and intracellular ATP content between two groups (Fig. 4 and Fig. 5), although VSL, VCL, and VAP of spermatozoa incubated with anti-VDAC antibody decreased significantly.

\section{Discussion}

In the present study, the relationship between VDAC and human sperm motility was studied through in vitro co-incubation of spermatozoa with anti-VDAC antibody. The VDAC antibody is a polyclonal antibody. According to the antibody datasheet, it can react with three VDAC isoforms in mammals. Considering the high homology and the unclear presence 


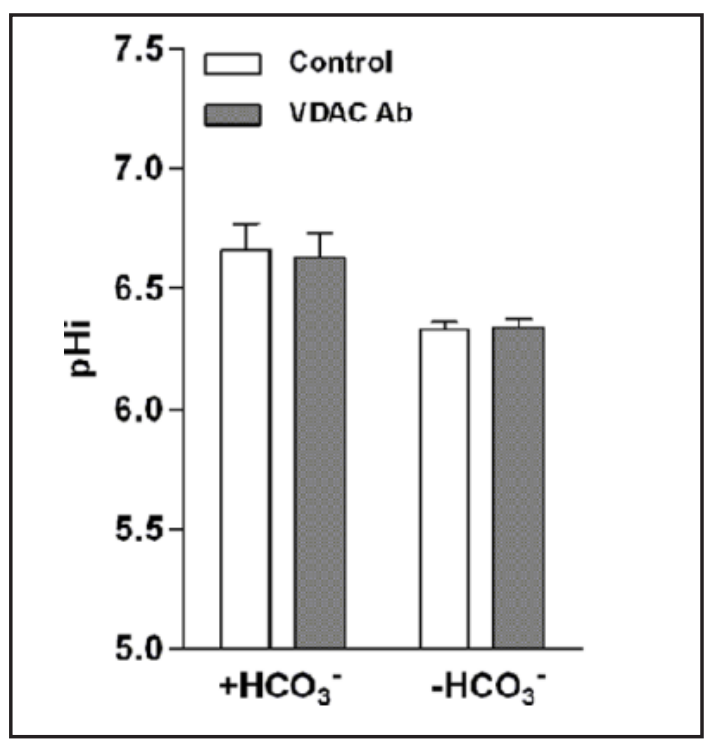

Fig. 4. pHi of human spermatozoa incubated with $20 \mu \mathrm{g} / \mathrm{ml}$ normal IgG or $20 \mu \mathrm{g} / \mathrm{ml}$ anti-VDAC antibody for $3 \mathrm{~h}$. Spermatozoa were measured using a microplate reader. Data are shown as mean \pm SEM. $\mathrm{n}=8 ; *, P<0.05$.

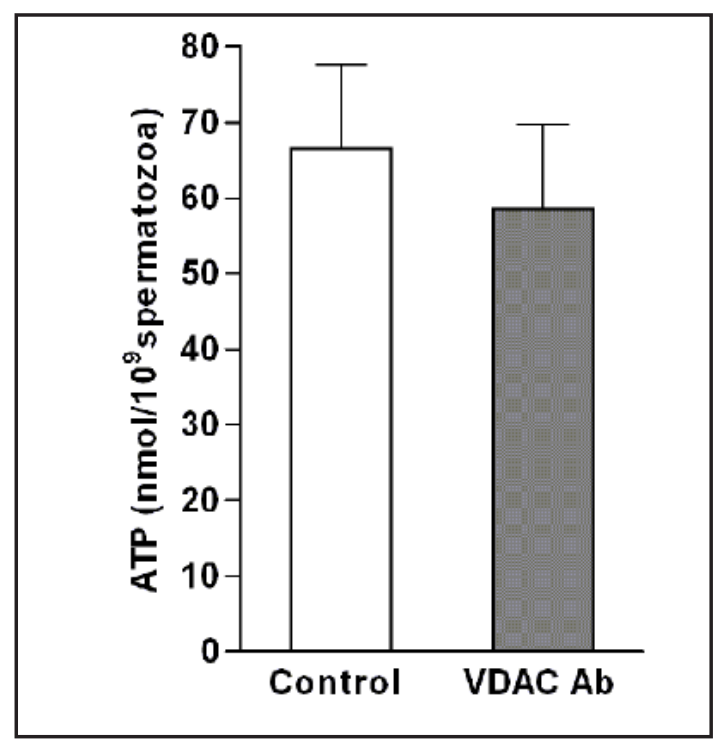

Fig. 5. Intracellular ATP contents of human spermatozoa incubated with $20 \mu \mathrm{g} / \mathrm{ml}$ normal IgG or $20 \mu \mathrm{g} /$ $\mathrm{ml}$ anti-VDAC antibody for $3 \mathrm{~h}$. Spermatozoa were measured using a Luminometer. Data are shown as mean \pm SEM. $n=8$.

and location of VDAC isoforms in human sperm, this antibody may be more effective and suitable for the purposes of the present study than other antibodies. Immunofluorescence initially demonstrated the affinity of antibody to spermatozoa. The binding site was the midpiece surface of sperm flagellum. VDAC existed in plasma membranes of some somatic cells other than the mitochondria [6-8]. Similar results were observed in a previous study, in which specific antibody was detected VDAC in plasma membrane of human spermatozoa [24]. Immunofluorescence data from the present work suggested that VDAC existed on the membrane surface of flagellar midpiece. However, this was not entirely consistent with the results of the previous study, in which the staining was observed throughout the sperm tail [23]. The different antibody and experimental methods (permeabilization to sperm membrane using Triton X-100 in the previous study) may have led to other differences.

Further study showed that co-incubation significantly reduced VSL, VCL, and VAP. It suggested that VDAC on the midpiece surface participated in the modulation of sperm motility. It is here noted that total sperm motility did not show obvious changes, unlike the case of mice lacking VDAC3, which had reduced total sperm motility [19]. Different experimental methods and species might have different results. The selected spermatozoa were subjected to a discontinuous Percoll gradient and found to be highly motile. Although antibody co-incubation interfered with movement ability, not all spermatozoa lost all motility. In this way, only the more sensitive indexes (VSL, VCL, and VAP) were able to reflect this influence accurately. For example, grade a spermatozoa can change to grade $b$ or grade $c$ spermatozoa after co-incubation. However, the total motility (grade $a+b+c$ spermatozoa) can remain unchanged. Motility refers to the capacity for forward movement. VSL, VCL and VAP can refer to the amplitude and asymmetry of the flagellar beating, which are the parameters of hyperactivation. Two kinds of indexes reflect different characteristics of the movement of spermatozoa. It has been demonstrated that reduced VSL, VCL, and VAP are associated with impaired ability of sperm to perform fertilization [27, 28]. In this way, the present data also suggest the close relationship between VDAC and fertilization.

Appropriate $\left[\mathrm{Ca}^{2+}\right]_{i}$, pHi, and intracellular ATP content are essential to maintaining sperm motility [29]. It depends on the normal transmembrane transport and exchange of $\mathrm{Ca}^{2+}, \mathrm{H}^{+}$/ 
$\mathrm{HCO}_{3}{ }^{-}$, and ATP mediated by relative transmembrane ion channels. Antibody incubation can disturb the normal function of these channels $[16,17]$. VDAC is a typical transmembrane ion channel. Further research on the mechanism of antibody-impaired sperm motility through detecting $\left[\mathrm{Ca}^{2+}\right]_{\mathrm{i}^{\prime}}$ pHi, and intracellular ATP is merited.

$\left[\mathrm{Ca}^{2+}\right]_{\mathrm{i}}$ has a positive correlation with sperm motility $[30,31]$. Flagellar beating and swimming velocity is triggered and maintained by $\mathrm{Ca}^{2+}$ transmembrane flow. VDAC in somatic cells can bind to and transport $\mathrm{Ca}^{2+}$. VDAC in human spermatozoa may regulate sperm motility through a similar mechanism. In the present study, reduced $\left[\mathrm{Ca}^{2+}\right]_{i}$ in spermatozoa with impaired motility suggested that co-incubation inhibited $\mathrm{Ca}^{2+}$ flow, a typical feature of this channel protein. VDAC might modulate human sperm motility through mediation of $\mathrm{Ca}^{2+}$ transmembrane transport and exchange. However, different types of $\mathrm{Ca}^{2+}$ channels exist in spermatozoa. These include CatSper, NCX, and SOCC [32-34]. The exact mechanism by which VDAC influences sperm calcium homeostasis and the relationship between VDAC and other $\mathrm{Ca}^{2+}$ channels in the modulation of sperm motility merit further study.

$\mathrm{pHi}$ is closely related to sperm motility. There are several mechanisms by which $\mathrm{pHi}$ is regulated, such as $\mathrm{Na}^{+} / \mathrm{H}^{+}$exchange, $\mathrm{Na}^{+}$-independent $\mathrm{Cl}^{-} / \mathrm{HCO}_{3}{ }^{-}$exchange, and $\mathrm{Na}^{+}$-dependent $\mathrm{Cl}^{-} / \mathrm{HCO}_{3}^{-}$exchange $[16,35,36]$. $\mathrm{HCO}_{3}^{-}$plays a key role in the regulation of pHi. During migration, spermatozoa pass through an increasing gradient of $\mathrm{HCO}_{3}^{-}$from the epididymis to the uterus and oviduct [37]. Increased $\mathrm{HCO}_{3}^{-}$levels promote $\mathrm{HCO}_{3}{ }^{-}$influx, increases in pHi and sperm movement, and vice versa [17]. In the present study, co-incubation did not affect pHi of human spermatozoa regardless of the presence or absence of $\mathrm{HCO}_{3}{ }^{-}$. The data indicated that VDAC might not participate in $\mathrm{H}^{+} / \mathrm{HCO}_{3}{ }^{-}$transmembrane transport.

ATP provides the energy for sperm motility. Abnormal ATP production and utilization can impair sperm motility. Mitochondria on the midpiece of the sperm flagellum can produce ATP through aerobic oxidation. In the present study, the concentration of intracellular ATP was loser in human spermatozoa incubated with anti-VDAC antibody, which was consistent with impaired motility. However, the difference was not statistically significant. It is here speculated that the binding of anti-VDAC antibody to the surface of the midpiece did not interfere with ATP production by the mitochondria in the midpiece under the cellular membrane. The mitochondria were not the only source of ATP. Glycolysis was carried out along the fibrous sheaths of the principal piece to supply ATP for sperm motility [38]. Even if antibody incubation disrupts ATP production or utilization, intracellular ATP content may not be severely influenced.

In conclusion, the present work explores the relationship between VDAC and human sperm motility. VDAC antibody can bind to the surface of the midpiece of human sperm flagella and reduce sperm motility by inhibiting $\mathrm{Ca}^{2+}$ transmembrane flow. The present study shows that VDAC participates in the modulation of human sperm motility by mediating $\mathrm{Ca}^{2+}$ transmembrane transport and exchange. Further research about the role and mechanism of VDAC in human spermatozoa will be beneficial to determining the pathogenesis of certain types of idiopathic male infertility with asthenozoospermia and developing new diagnostic and therapeutic methods.

\section{Conflict of Interest}

The authors declare no conflict of interest.

\section{Acknowledgements}

This work was supported by the grant from National Natural Science Foundation of China (81200467) and by A Project Funded by the Priority Academic Program Development of Jiangsu Higher Education Institutions (JX10231801). 


\section{Cellular Physiology and Biochemistry}

Liu et al.: VDAC and Human Sperm Motility

\section{References}

1 Sorgato MC, Moran 0: Channels in mitochondrial membranes: knowns, unknowns, and prospects for the future. Crit Rev Biochem Mol Biol 1993;28:127-171.

-2 Rostovtseva T, Colombini M: ATP flux is controlled by a voltage-gated channel from the mitochondrial outer membrane. J Biol Chem 1996;271:28006-28008.

-3 Tsujimoto Y, Shimizu S: The voltage-dependent anion channel: an essential player in apoptosis. Biochimie 2002;84:187-193.

4 Pavlov E, Grigoriev SM, Dejean LM, Zweihorn CL, Mannella CA, Kinnally KW: The mitochondrial channel VDAC has a cation-selective open state. Biochim Biophys Acta 2005;1710:96-102.

-5 Shoshan-Barmatz V, De Pinto V, Zweckstetter M, Raviv Z, Keinan N, Arbel N: VDAC, a multi-functional mitochondrial protein regulating cell life and death. Mol Aspects Med 2010;31:227-285.

-6 Báthori G, Parolini I, Szabó I, Tombola F, Messina A, Oliva M, Sargiacomo M, De Pinto V, Zoratti M: Extramitochondrial porin: facts and hypotheses. J Bioenerg Biomembr 2000;32:79-89.

7 De Pinto V, Messina A, Lane DJ, Lawen A: Voltage-dependent anion-selective channel (VDAC) in the plasma membrane. FEBS Lett 2010;584:1793-1799.

8 Kotake S, Yago T, Kawamoto M, Nanke Y: Voltage-dependent anion channels (VDACs, porin) expressed in the plasma membrane regulate the differentiation and function of human osteoclasts. Cell Biol Int 2013;37:65-77.

-9 Guarino F, Specchia V, Zapparoli G, Messina A, Aiello R, Bozzetti MP, De Pinto V: Expression and localization in spermatozoa of the mitochondrial porin isoform 2 in Drosophila melanogaster. Biochem Biophys Res Commun 2006;346:665-670.

10 Hinsch KD, De Pinto V, Aires VA, Schneider X, Messina A, Hinsch E: Voltage-dependent anion-selective channels VDAC2 and VDAC3 are abundant proteins in bovine outer dense fibers, a cytoskeletal component of the sperm flagellum. J Biol Chem 2004;279:15281-15288.

-11 Triphan X, Menzel VA, Petrunkina AM, Cassará MC, Wemheuer W, Hinsch KD, Hinsch E: Localisation and function of voltage-dependent anion channels (VDAC) in bovine spermatozoa. Pflugers Arch 2008;455:677-686.

$\checkmark 12$ Menzel VA, Cassará MC, Benz R, de Pinto V, Messina A, Cunsolo V, Saletti R, Hinsch KD, Hinsch E: Molecular and functional characterization of VDAC2 purified from mammal spermatozoa. Biosci Rep 2009;22:351362 .

13 Liu B, Zhang W, Wang Z: Voltage-dependent anion channel in mammalian spermatozoa. Biochem Biophys Res Commun 2010;397:633-636.

14 Kwon WS, Park YJ, Mohamed el-SA, Pang MG: Voltage-dependent anion channels are a key factor of male fertility. Fertil Steril 2013;99:354-361.

15 Tosti E, Boni R: Electrical events during gamete maturation and fertilization in animals and humans. Hum Reprod Update 2004;10:53-65.

16 Zeng Y, Oberdorf JA, Florman HM: pH regulation in mouse sperm: identification of $\mathrm{Na}^{+}-$, $\mathrm{Cl}^{--}$, and $\mathrm{HCO}_{3}^{-}$ dependent and arylaminobenzoate-dependent regulatory mechanisms and characterization of their roles in sperm capacitation. Dev Biol 1996;173:510-520.

17 Luconi M, Porazzi I, Ferruzzi P, Marchiani S, Forti G, Baldi E: Tyrosine phosphorylation of the A kinase anchoring protein 3 (AKAP3) and soluble adenylate cyclase are involved in the increase of human sperm motility by bicarbonate. Biol Reprod 2005;72:22-32.

18 Gogol P, Szcześniak-Fabiańczyk B, Wierzchoś-Hilczer A: The photon emission, ATP level and motility of boar spermatozoa during liquid storage. Reprod Biol 2009;9:39-49.

19 Sampson MJ, Decker WK, Beaudet AL, Ruitenbeek W, Armstrong D, Hicks MJ, Craigen WJ: Immotile sperm and infertility in mice lacking mitochondrial voltage-dependent anion channel type 3. J Biol Chem 2001;276:39206-39212.

20 Gincel D, Zaid H, Shoshan-Barmatz V: Calcium binding and translocation by the voltage-dependent anion channel: a possible regulatory mechanism in mitochondrial function. Biochem J 2001;358:147-155.

21 Israelson A, Abu-Hamad S, Zaid H, Nahon E, Shoshan-Barmatz V: Localization of the voltage-dependent anion channel-1 $\mathrm{Ca}^{2+}$-binding sites. Cell Calcium 2007;41:235-244. 
Liu et al.: VDAC and Human Sperm Motility

22 Rostovtseva TK, Sheldon KL, Hassanzadeh E, Monge C, Saks V, Bezrukov SM, Sackett DL: Tubulin binding blocks mitochondrial voltage-dependent anion channel and regulates respiration. Proc Natl Acad Sci USA 2008;105:18746-18751.

23 Liu B, Wang Z, Zhang W, Wang X: Expression and localization of voltage-dependent anion channels (VDAC) in human spermatozoa. Biochem Biophys Res Commun 2009;378:366-370.

24 Liu B, Wang P, Wang Z, Zhang W: The use of anti-VDAC2 antibody for the combined assessment of human sperm acrosome integrity and ionophore A23187-induced acrosome reaction. PLoS ONE 2011;6:e16985.

25 World Health Organization: WHO laboratory manual for the examination and processing of human semen. 5th ed. Switzerland, WHO Press, 2010.

-26 Demarco IA, Espinosa F, Edwards J, Sosnik J, De La Vega-Beltran JL, Hockensmith JW, Kopf GS, Darszon A, Visconti PE: Involvement of a $\mathrm{Na}^{+} / \mathrm{HCO}_{3}{ }^{-}$cotransporter in mouse sperm capacitation. J Biol Chem 2003;278:7001-7009.

27 Moore HD, Akhondi MA: Fertilizing capacity of rat spermatozoa is correlated with decline in straight-line velocity measured by continuous computer-aided sperm analysis: epididymal rat spermatozoa from the proximal cauda have a greater fertilizing capacity in vitro than those from the distal cauda or vas deferens. J Androl 1996;17:50-60.

28 Hirano Y, Shibahara H, Obara H, Suzuki T, Takamizawa S, Yamaguchi C, Tsunoda H, Sato I: Relationships between sperm motility characteristics assessed by the computer-aided sperm analysis (CASA) and fertilization rates in vitro. J Assist Reprod Genet 2001;18:213-218.

-29 Inaba K: Molecular architecture of the sperm flagella: molecules for motility and signaling. Zoolog Sci 2003;20:1043-1056.

-30 Ho HC, Suarez SS: Characterization of the intracellular calcium store at the base of the sperm flagellum that regulates hyperactivated motility. Biol Reprod 2003;68:1590-1596.

31 Krasznai Z, Krasznai ZT, Morisawa M, Bazsáné ZK, Hernádi Z, Fazekas Z, Trón L, Goda K, Márián T: Role of the $\mathrm{Na}^{+} / \mathrm{Ca}^{2+}$ exchanger in calcium homeostasis and human sperm motility regulation. Cell Motil Cytoskeleton 2006;63:66-76.

-32 Ren D, Navarro B, Perez G, Jackson AC, Hsu S, Shi Q Tilly JL, Clapham DE: A sperm ion channel required for sperm motility and male fertility. Nature 2001;413:603-609.

-33 Carlson AE, Westenbroek RE, Quill T, Ren D, Clapham DE, Hille B, Garbers DL, Babcock DF: CatSper1 required for evoked $\mathrm{Ca}^{2+}$ entry and control of flagellar function in sperm. Proc Natl Acad Sci USA 2003;100:14864-14868.

34 Yoshida M, Ishikawa M, Izumi H, De Santis R, Morisawa M: Store-operated calcium channel regulates the chemotactic behavior of ascidian sperm. Proc Natl Acad Sci USA 2003;100:149-154.

-35 Chen WY, Xu WM, Chen ZH, Ni Y, Yuan YY, Zhou SC, Zhou WW, Tsang LL, Chung YW, Höglund P, Chan HC, Shi QX: $\mathrm{Cl}^{-}$is required for $\mathrm{HCO}_{3}$ - entry necessary for sperm capacitation in guinea pig: involvement of a $\mathrm{Cl}^{-} /$ $\mathrm{HCO}_{3}{ }^{-}$exchanger (SLC26A3) and CFTR. Biol Reprod 2009;80:115-123.

-36 Liu T, Huang JC, Zuo WL, Lu CL, Chen M, Zhang XS, Li YC, Cai H, Zhou WL, Hu ZY, Gao F, Liu YX: A novel testis-specific $\mathrm{Na}^{+} / \mathrm{H}^{+}$exchanger is involved in sperm motility and fertility. Front Biosci (Elite Ed) 2010;2:566-581.

-37 Wang XF, Zhou CX, Shi QX, Yuan YY, Yu MK, Ajonuma LC, Ho LS, Lo PS, Tsang LL, Liu Y, Lam SY, Chan LN, Zhao WC, Chung YW, Chan HC: Involvement of CFTR in uterine bicarbonate secretion and the fertilizing capacity of sperm. Nat Cell Biol 2003;5:902-906.

-38 Miki K, Qu W, Goulding EH, Willis WD, Bunch DO, Strader LF, Perreault SD, Eddy EM, O’Brien DA: Glyceraldehyde 3-phosphate dehydrogenase-S, a spermspecific glycolytic enzyme, is required for sperm motility and male fertility. Proc Natl Acad Sci USA 2004;101:16501-16506. 